\title{
ANALISIS PERBANDINGAN MUTU BETON DENGAN MENGGUNAKAN BERBAGAI CARA PENGADUKAN (READY MIX, MOLEN DAN MANUAL)
}

\author{
Oleh: \\ Rahelina Ginting 1), \\ Winarko Malau ${ }^{2}$ ' \\ Uniersitas Darma Agung, Medan ${ }^{1,2)}$ \\ E-mail: \\ grahelina77@gmail.com ${ }^{1)}$ \\ sihombingdahlia24@gmail.com ${ }^{2)}$
}

\begin{abstract}
Concrete work is widely used in construction projects now. To get a good quality concrete depends very much on the quality of the constituent materials, namely cement, water, fine aggregate, coarse aggregate, and also the process of working or stirring. In this research, $27 \mathrm{MPa}$ concrete compressive strength will be investigated with various stirring methods (Manual Mix, Molen Mix and Ready Mix). These three methods of stirring certainly have their respective uses in the process, usually Manual, Molen and Ready Mix are used depending on the conditions of the project being worked on. From this test, results are obtained by means of manual stirring, Molen stirring and Ready Mix with compressive strength average: $(266,467 \mathrm{~kg} / \mathrm{cm} 2)(278,368 \mathrm{~kg} / \mathrm{cm} 2)$ $(284,595 \mathrm{~kg} / \mathrm{cm} 2)$. The results of the study stated that the research carried out fulfilled the estimation target 'c $=27 \mathrm{Mpa}$.
\end{abstract}

\section{Keywords: Manual Mix, Molen Mix, Ready-Mix}

\section{ABSTRAK}

Pekerjaan beton banyak dipergunakan dalam proyek pembangunan sekarang ini. Untuk mendapatkan kualitas beton yang baik sangat tergantung oleh kualitas dari bahan-bahan penyusunnya yaitu semen, air, agregat halus, agregat kasar, dan juga proses pengerjaan atau pengadukannya.Cara pengadukan dalam pembuatan beton harus diperhatikan guna mendapatkan kuat tekan beton sesuai rencana. Dalam penelitian ini akan diteliti perbedaan kuat tekan beton f'c $27 \mathrm{MPa}$ dengan berbagai cara pengadukan (Adukan Manual, adukan Molen dan adukan Ready Mix). Ketiga cara pengadukan tersebut tentunya mempunyai kegunaan masing-masing dalam pengerjaannya, biasanya adukan Manual, Molen dan Ready Mix digunakan tergantung kondisi atau keadaan project yang dikerjakan.Dari pengujian ini didapat hasil pengujian dengan cara pengadukan manual, adukan Molen dan adukan Ready Mix dengan kuat tekan rata-rata :(266.467 Kg/cm2) $\left(278.368 \mathrm{Kg} / \mathrm{cm}^{2}\right)\left(284.595 \mathrm{Kg} / \mathrm{cm}^{2}\right)$. Hasil penelitian menyatakan bahwa penelitian yang dilakukan memenuhi target estimasif'c $=27 \mathrm{Mpa}$.

Kata Kunci : Adukan Manual,Adukan Molen, Adukan Ready-Mix.

\section{PENDAHULUAN}

Cara pengadukan campuran beton

biasanya dapat dilakukan dengan tiga cara yaitu : beton menggunakan jasa perusahaan beton segar (Ready Mix), beton menggunakan adukan mesin 
"Molen" dan beton menggunakan adukan "Manual".

Pada perusahaan penyedia beton segar (Ready mix) biasanya banyak menggunakan bahan tambah untuk memperoleh beton yang memiliki kuat awal tinggi (early strength concrete) serta pengerjaan pada saat pengecoran mudah (workability). Penggunaan bahan tambah ini tidak hanya untuk mempermudah pengerjaan pada saat pengecoran di sebuah proyek pembangunan, fungsi lain dari bahan tambah ini adalah untuk menunda waktu ikat (initial setting) dari adukan beton dan juga mengurangi jumlah air yang dipakai, namun tetap dalam pengerjaannya akan mudah.

Cara adukan menggunakan molen adalah pengadukan beton dengan menggunakan mesin. Pada umumnya adukan dengan menggunakan molen, para pekerjaannya memiliki urutan yang nantinya tidak menyisakan adukan dalam jumlah yang banyak atau melekatnya adukan pada dinding alat pengaduk beton (Molen) dan dengan cepat tercampur secara merata.

Biasanya penggunaan adukan Ready mix, adukan "Molen" dan adukan "Manual" digunakan tergantung kondisi atau keadaan project yang dikerjakan tanpa mengurangi kualitas beton.

\section{TINJAUAN PUSTAKA}

Campuran beton yakni air, semen, agregat (kasar dan halus) dan bahan tambah (admixture) apabila diperlukan. Semen bila bercampur air membentuk pasta semen yang berfungsi sebagai pengikat. Bahan pengisi dan penguat adalah agregat kasar dan halus. Bahanbahan yang dipilih sesuai dengan kebutuhan yang direncanakan.

Beton mempunyai kekuatan yang besar, sebelum beton mengeras, campuran beton masih plastis. Kemudian beton mengalami proses pengikatan hingga beton menjadi keras.

\section{Pengadukan Manual}

Menggunakan peralatan yang sederhana dengan tenaga manusia. Pengadukan Manual masih digunakan sampai sekarang, pelaksanaannya sangat mudah. Pengadukan manual untuk mutu beton yang rendah dan volume pekerjaan kecil, supaya pengerjaan dan kerataan aduk mudah dicapai.

Yang perlu diperhatikan dalam pekerjaan manual kerataan pencampuran bahannya, bila masih ada perbedaan warna maka campuran tersebut belum rata. Jika belum rata 
pengadukan dilakukan kembali.

Pengadukan beton cara manual menggunakan perbandingan volume air, pasir, semen dan kerikil.

\section{Pengadukan Menggunakan Mesin} Molen

Pengadukan menggunakan mesin Molen (mixer) dilaksanakan untuk pengecoran beton struktur, dan volume pengecoran yang cukup besar. Dibandingkan dengan pengadukan manual hasil pengadukan menggunakan Molen akan lebih baik, adukan lebih merata dan homogen. volume pengadukan lebih banyak serta nilai kokohnya 20-50\% lebih besar.

\section{Pengadukan dengan Ready Mix}

Beton dengan ready-mix merupakan beton segar yang belum mengalami proses perkerasan dan pengikatan diproduksi di batching plant dengan penambahan admixture (bahan kimia), tergantung jenis beton yang dipesan. Beton ready-mix diproduksi di pabrik dengan pengawasan menggunakan sistem operasi computer, pengiriman kelapangan dengan menggunakan truk mixer.

Workability

Workability tingkat kemudahan pengerjaan campuran beton proses pengadukan penuangan, pengangkutan, dan pemadatan.

\section{Faktor Air Semen}

Faktor air semen perbandingan berat dari air dan berat dari semen dalam adukan beton. fas yang tinggi menyebabkan mutu beton rendah dan semakin rendah fas kuat tekan beton semakin tinggi. Namun nilai fas yang semakin rendah tidak berarti nilai kuat tekan beton semakin tinggi. Nilai fas rendah mempengaruhi dalam pengerjaan, kesulitan dalam pelaksanaan pemadatan yang akhirnya akan menyebabkan mutu beton menurun. Oleh sebab itu ada fas optimum untuk menghasilkan kuat tekan maksimum. Umumnya nilai fas minimum untuk beton normal sekitar 0,4 dan maksimum 0.65 (Tri Mulyono, 2003).

Hubungan antara factor air semen dengan kuat tekan beton dapat dituis dengan rumus Duff Abrams (1919) sebagai berikut :

$\mathrm{f}^{\prime} \mathrm{c}=\frac{X}{A}$ $\operatorname{Per}(1.1)$

Keterangan :

f'c : Kuat tekan beton (Mpa)

$\mathrm{X}$ : Faktor air semen

A,B : Konstanta

Semakin besar faktor air semen semakin rendah kuat tekan betonnya, 
walaupun apabila dilihat dari rumus tersebut tampak bahwa semakin kecil faktor air semen semakin tinggi kuat tekan beton, tetapi nilai fas yang rendah akan menyulitkan pemadatan, sehingga kekuatan tekan beton akan rendah karena beton kurang padat.

\section{Slump}

Slump digunakan untuk mengetahui tingkat kelecakan suatu adukan beton, semakin tinggi tingkat kekenyalan maka semakin mudah pengerjaannya (nilai workability tinggi).

\section{Kuat Tekan Beton}

Kuat tekan beton merupakan perbandingan tingkatan beban yang diberikan dengan luas penampang. Kuat tekan beton biasanya berhubungan dengan sifat-sifat lain, maksudnya apabila kuat tekan beton tinggi, sifatsifat lainnya juga baik. Kekuatan tekan beton dapat dicapai sampai $1000 \mathrm{~kg} / \mathrm{cm}^{2}$ atau lebih, tergantung pada jenis campuran, sifat agregat, serta kualitas perawatan.

Kekuatan tekan beton yang paling umum digunakan adalah sekitar 200$500 \mathrm{~kg} / \mathrm{cm}^{2}$. Nilai kuat tekan beton didapatkan melalui tata cara pengujian standar, menggunakan mesin uji dengan cara memberikan beban tekan bertingkat dengan kecepatan peningkatan beban tertentu dengan benda uji berupa silinder $150 \times 300$ $\mathrm{mm}$. Selanjutnya benda uji ditekan dengan mesin tekan sampai pecah. Beban tekan maksimum sampai benda uji pecah dibagi dengan luas penampang benda uji merupakan nilai kuat tekan beton yang dinyatakan dalam Mpa atau $\mathrm{kg} / \mathrm{cm}^{2}$. Tata cara pengujian yang umum dipakai adalah standar ASTM C.39 atau menurut yang dinyatakan PBI 1989 dan Ginting R (2019).

Rumus yang digunakan untuk perhitungan kuat tekan beton adalah :

$\mathrm{f}^{\prime} \mathrm{c}=-\ldots \ldots \ldots \ldots \ldots \ldots \ldots \ldots \operatorname{Pers}(1.2)$

Keterangan :

f;c : Kuat Tekan Beton (Mpa)

$\mathrm{P} \quad$ : Beban maksimum $(\mathrm{Kn})$

A : Luas Penampang Benda uji $\left(\mathrm{cm}^{2}\right)$

\section{METODE PELAKSANAAN}

Metode pelaksanaan dalam penelitian ini adalah Kajian analisa di Laboratorium Bahan Rekayasa Departemen Fakultas Teknik Sipil Universitas Darma Agung dan Laboratorium Bahan Rekayasa Departemen Batching Plant PT. Duta BetonSejati. 
4. HASIL DAN PEMBAHASAN

Hasil Perhitungan Perancangan

Campuran Beton (Mix Design

Concrete)

Benda uji design secara teoritis yang mengacu pada Standard Nasional
Indonesia (SNI 03-2834-2000) tentang Tata Cara Pembuatan Beton Normal dan Beton Campuran. Mutu beton yang diisyaratkan untuk benda uji silinder adalah f'c $=27 \mathrm{Mpa}$.

Tabel Hasil Perencanaan Mix Design Beton Normal

\begin{tabular}{|c|c|c|}
\hline No & Uraian & Nilai \\
\hline 1 & $\begin{array}{c}\text { Kuattekan yang diisyaratkan } \\
\text { (bendaujisilinder) }\end{array}$ & 27Mpapada 28 hari \\
\hline 2 & Kekuatan rata-rata (fcr) & 27 Mpa \\
\hline 3 & Jenis semen & Semen portlandtipe I \\
\hline & Jenisagregat : & -Batupecah \\
& -Kasar & - Pasirbeton \\
\hline 5 & -Halus & 0,54 \\
\hline 6 & Faktor air semen bebas & $60-180$ \\
\hline 7 & Slump & $20 \mathrm{~mm}$ \\
\hline 8 & Ukuran agregat maksimum & $225 \mathrm{~kg} / \mathrm{m}^{3}$ \\
\hline 9 & Kadar air bebas & $416.667 \mathrm{~kg} / \mathrm{m}^{3}$ \\
\hline 10 & Kadar Semen & $47,5 \%$ \\
\hline 11 & Persen agregat kasar & $2400 \mathrm{~kg} / \mathrm{m}^{3}$ \\
\hline 12 & Beratisi beton & $52,5 \%$ \\
\hline 13 & Persenagregathalus & $1758,333 \mathrm{~kg} / \mathrm{m}^{3}$ \\
\hline 14 & Kadar agregat gabungan & $923,125 \mathrm{~kg} / \mathrm{m}^{3}$ \\
\hline 15 & Kadar agregat halus & $835,193 \mathrm{~kg} / \mathrm{m}^{3}$ \\
\hline 16 & Kadar agregat kasar & $225 \mathrm{~kg} / \mathrm{m}^{3}$ \\
\hline
\end{tabular}

Untuk 1 silinder, volume campuran yang dibutuhkan adalah :

Volume 1 bendauji = 1 silinder $\mathrm{x}$ volume silinder

$=1 \times 0,00529875=0,00529875 \mathrm{~m}^{3}$

Tabel Kadar Agregat Campuran Untuk Sekali Adukan

Membuat Silinder Benda Uji

\begin{tabular}{|c|c|c|c|}
\hline \multirow{2}{*}{ Bahan } & \multicolumn{3}{|c|}{ Agregat } \\
\cline { 2 - 4 } & $\begin{array}{c}\text { Mix Design } \\
\text { Normal (3 } \\
\text { Silinder) }\end{array}$ & $\begin{array}{c}\text { Mix Design } \\
\text { Dengan adukan } \\
\text { Molen(12 } \\
\text { Silinder) }\end{array}$ & $\begin{array}{c}\text { Mix Design } \\
\text { DenganAdukan } \\
\text { Ready Mix (12 } \\
\text { silinder) }\end{array}$ \\
\hline Air $(\mathrm{Kg})$ & 4,293 & 17,172 & 17,172 \\
\hline Semen $(\mathrm{Kg})$ & 8,417 & 31,800 & 31,800 \\
\hline
\end{tabular}




\begin{tabular}{|c|c|c|c|}
\hline Pasir $(\mathrm{Kg})$ & 17,367 & 70,453 & 70,453 \\
\hline Kerikil $(\mathrm{Kg})$ & 15,713 & 63,742 & 63,742 \\
\hline
\end{tabular}

Tabel Nilai Slump dari masing-masing perlakuan

\begin{tabular}{|c|c|}
\hline 3 Komposisi Agregat & Nilai Slump (cm) \\
\hline Adukan Manual & 10 \\
\hline Adukan Molen & 13 \\
\hline Adukan Ready Mix & 12 \\
\hline
\end{tabular}

\section{Hasil Perhitungan Kuat Tekan Beton}

Tabel Kuat Tekan Beton Adukan Manual

\begin{tabular}{|c|c|c|c|c|c|}
\hline Kode & $P(K n)$ & $A\left(\mathrm{~cm}^{2}\right)$ & $\begin{array}{c}\mathbf{P} \\
(\mathrm{Kg} / \mathrm{cm} 2)\end{array}$ & $\begin{array}{c}\sigma \mathbf{b} \\
\text { Mpa }\end{array}$ & Umur \\
\hline 1 & 23154 & 176.625 & 131.091 & 13.377 & \multirow{4}{*}{3 Hari } \\
\hline 2 & 23835 & 176.625 & 134.947 & 13.770 & \\
\hline 3 & 24062 & 176.625 & 136.232 & 13.901 & \\
\hline \multicolumn{3}{|c|}{ Rata-Rata } & 134.090 & 13.683 & \\
\hline 4 & 35412 & 176.625 & 200.493 & 20.458 & \multirow{4}{*}{7 Hari } \\
\hline 5 & 34958 & 176.625 & 197.922 & 20.196 & \\
\hline 6 & 35412 & 176.625 & 200.493 & 20.458 & \\
\hline \multicolumn{3}{|c|}{ Rata-Rata } & 199.636 & 20.371 & \\
\hline 7 & 39498 & 176.625 & 223.626 & 22.819 & \multirow{4}{*}{14 Hari } \\
\hline 8 & 39498 & 176.625 & 223.626 & 22.819 & \\
\hline 9 & 39044 & 176.625 & 221.464 & 22.557 & \\
\hline \multicolumn{3}{|c|}{ Rata-Rata } & 222.770 & 22.732 & \\
\hline 10 & 48124 & 176.625 & 272.464 & 27.802 & \multirow{4}{*}{28 Hari } \\
\hline 11 & 47670 & 176.625 & 269.894 & 27.540 & \\
\hline 12 & 45400 & 176.625 & 257.042 & 26.229 & \\
\hline \multicolumn{3}{|c|}{ Rata-Rata } & 266.467 & 27.190 & \\
\hline
\end{tabular}

Tabel Kuat TekanBetonAdukanMesinMolen

\begin{tabular}{|c|c|c|c|c|c|}
\hline Kode & $\mathbf{P}(\mathbf{K n})$ & $A\left(\mathrm{~cm}^{2}\right)$ & $\begin{array}{c}P \\
(\mathrm{Kg} / \mathrm{cm} 2)\end{array}$ & $\begin{array}{c}\sigma \mathbf{b} \\
\text { Mpa }\end{array}$ & Umur \\
\hline 1 & 24000 & 176.625 & 135.881 & 13.865 & \multirow{4}{*}{3 Hari } \\
\hline 2 & 24500 & 176.625 & 138.712 & 14.154 & \\
\hline 3 & 23900 & 176.625 & 135.315 & 13.808 & \\
\hline \multicolumn{3}{|c|}{ Rata-Rata } & 136.636 & 13.942 & \\
\hline 4 & 36300 & 176.625 & 205.520 & 20.971 & \multirow{4}{*}{7 Hari } \\
\hline 5 & 35500 & 176.625 & 200.991 & 20.509 & \\
\hline 6 & 36000 & 176.625 & 203.822 & 20.798 & \\
\hline \multicolumn{3}{|c|}{ Rata-Rata } & 203.444 & 20.760 & \\
\hline 7 & 41500 & 176.625 & 234.961 & 23.976 & \multirow{2}{*}{14 Hari } \\
\hline 8 & 41000 & 176.625 & 232.130 & 23.687 & \\
\hline
\end{tabular}




\begin{tabular}{|c|c|c|c|c|c|}
\hline 9 & 41300 & 176.625 & 280.255 & 23.860 & \\
\hline \multicolumn{3}{|c|}{ Rata-Rata } & 233.640 & 23.841 & \\
\hline 10 & 49500 & 176.625 & 280.255 & 28.597 & \multirow{4}{*}{28 Hari } \\
\hline 11 & 49000 & 176.625 & 277.424 & 28.309 & \\
\hline 12 & 49000 & 176.625 & 277.424 & 28.309 & \\
\hline \multicolumn{3}{|c|}{ Rata-Rata } & 278.368 & 28.405 & \\
\hline
\end{tabular}

Tabel Kuat Tekan Beton Adukan Ready-Mix

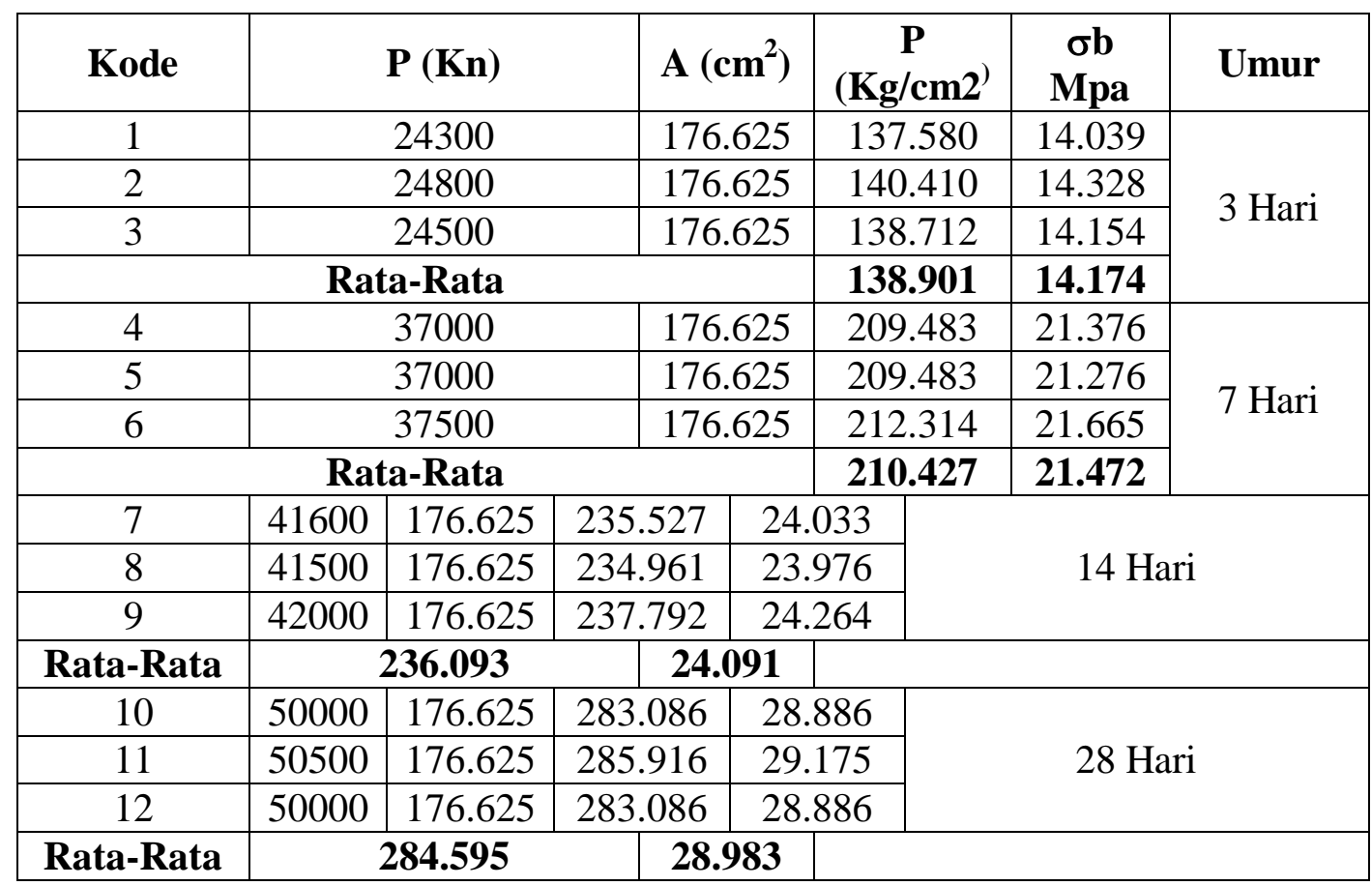

Tabel Rata-rata Kuat Tekan Beton Adukan Manual, Adukan Molen dan Adukan Ready-Mix

\begin{tabular}{|c|c|c|c|c|}
\hline $\begin{array}{c}\text { Jenis Adukan/ } \\
\text { Umur }\end{array}$ & 3 Hari & 7 Hari & 14 Hari & 28 Hari \\
\hline Manual & 13.683 & 20.371 & 22.732 & 27.190 \\
\hline Molen & 13.942 & 20.760 & 23.841 & 28.405 \\
\hline Ready Mix & 14.174 & 21.472 & 24.091 & 28.983 \\
\hline
\end{tabular}




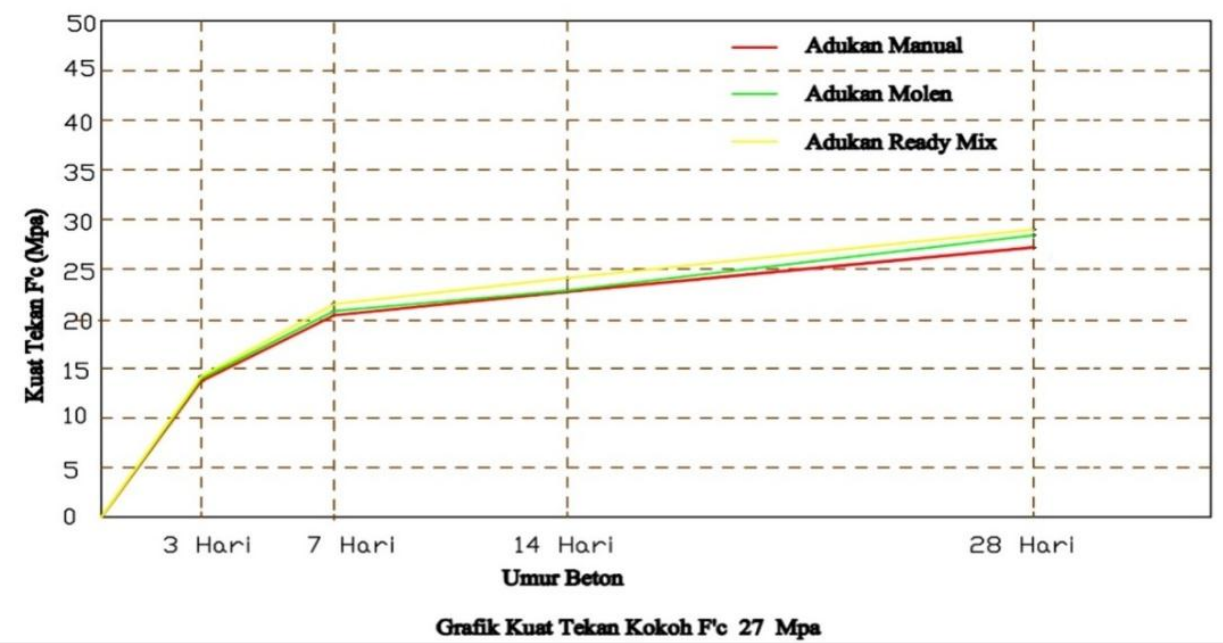

Grafik Kuat Tekan Kokoh F'c 27 Mpa

Tabel Kuat Tekan Beton

\begin{tabular}{|l|c|c|c|c|c|}
\hline \multirow{2}{*}{ Umur } & \multicolumn{5}{c|}{ Kuat Tekan Beton (Mpa) } \\
\cline { 2 - 7 } Jenis Adukan & 3 Hari & 7 Hari & 14 Hari & 28 Hari & $\%$ Kuat Tekan \\
\hline Adukan Manual & 13.683 & 20.371 & 22.732 & 27.190 & $6.186 \%$ \\
\hline Adukan Mesin Molen & 13.942 & 20.760 & 23.841 & 28.405 & $1.994 \%$ \\
\hline Adukan Ready Mix & 14.174 & 21.472 & 24.472 & 28.983 & - \\
\hline
\end{tabular}

\section{KESIMPULAN}

Berdasarkan hasil penelitian tentang cara pengadukan beton (Manual, Molen danReady-Mix) dapat disimpulkan bahwa :

1. Hasil Kuat tekan beton dengan cara pengadukan manual pada umur 28 hari diperoleh 27,190 Mpa.

2. Hasil Kuat tekan beton dengan cara pengadukan mesin molen pada umur 28 hari diperoleh 28,405 Mpa.

3. Hasil Kuat tekan beton dengan cara pengadukan mesin molen pada umur 28 hari diperoleh 28,983Mpa.

4. Disimpulkan bahwa beton dengan cara pengadukan Ready-Mix mempunyai kuat tekan beton yang lebih baik dibandingkan cara pengadukan lainnya.

5. Beton dengan ketiga cara pengadukan (Manual, Molendan Ready Mix) mempunyai kuat tekan beton yang tercapai dari kuat tekan beton rencana.

6. Dari Grafik 4.3 dapat disimpulkan perbedaan kuat tekan beton Ready Mix dengan adukan manual $=6.186 \%$, sedangkan perbedaan kuat tekan beton adukan Ready-Mix dengan adukan Molen $=1.994 \%$. 
7. Cara pengerjaan adukan Ready-Mix lebih gampang pekerjaannya dibandingkan dengan cara pengadukan Molen dan Manual.

\section{Saran}

1. Alat-alat yang digunakan dalam penelitian bahan-bahan pencampur beton supaya lebih lengkap guna mendapatkan hasil penelitian yang maksimal.

2. Lama waktu pengadukan supaya lebih diperhatikan sesuai Standar Waktu yang ditetapkan.

3. Alat yang digunakan hendaknya rutin dikalibrasi agar hasil penelitian lebih maksimal sesuai dengan yang direncanakan.

\section{DAFTAR PUSTAKA}

Departemen Pekerjaan Umum. 2002. "Tata Cara Pembuatan Rencana Campuran Beton Normal", SNI 03-2834-2000,Departemen

Pemukiman Dan Prasarana Wilayah, Badan Penelitian Dan Pengembangan, Jakarta.

SNI 03-2816-1992. "Analisa Dan Hasil Pengujian Pasir $\mathrm{NaOH}^{\circ}$
Departemen Pekerjaan Umum. 2002. "Metode, Spesifikasi Dan Tata CaraPembuatan Beton", Departemen Pemukiman Dan Prasarana Wilayah, Badan Penelitian Dan Pengembangan, Jakarta.

Mulyono, T. 2003. "Teknologi Beton", Fakultas Teknik Universitas Negri Jakarta, Jakarta.

RSNI (Rancangan Standart Nasional Indonesia). 2002. "Tata Cara Perencanaan Struktur Beton Untuk Bangunan Gedung”, Badan Standar Nasional, Jakarta.

SII (Standart Industri Indonesia). 005280. "Mutu Dan Cara Uji Agregat Beton".

SNI 03-2847-2002. "Tata Cara Perhitungan Strukrur Beton Untuk Bangunan Gedung”. 2009. Cetakan Kedua ISBN.

Ginting, R. (2019). KUAT TEKAN BETON DENGAN BESI TULANGAN D13. Jurnal Darma Agung, 27(2), 1012- 1024. Retrieved from https://jurnal.darmaagung.ac.id/in dex.php/jurnaluda/article/view/27 $\underline{5}$ 